\title{
A REVIEW OF AIR DISTRIBUTION PATTERNS IN SURGERY ROOMS UNDER INFECTION CONTROL FOCUS
}

\author{
M. L. Pereira ${ }^{a}$, \\ and A. Tribess ${ }^{\mathrm{b}}$ \\ ${ }^{a}$ Centro Federal de Educação \\ Tecnológica de Santa Catarina - CEFETSC \\ Rua José Lino Kretzer, 608 - Praia Comprida \\ 88103-902 - São José - Santa Catarina, Brasil \\ marcelo@sj.cefetsc.edu.br

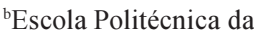 \\ Universidade de São Paulo \\ Departamento de Engenharia Mecânica \\ Av. Prof. Mello Moraes, 2231 \\ 05508-900 - São Paulo - SP, Brasil \\ atribess@usp.br
}

\begin{abstract}
The problem of airborne contamination in surgical infections still raises discussion. The success of the aseptic methods and the use of medicines for the combat of infections are making most surgeons contempt the danger of the aerial particles course. A detailed knowledge of the characteristics of the contamination sources and of the ventilation system performance used at surgery rooms is necessary to guarantee that the ventilation system supplies the pollutant control in ventilation rates that assure the health and the comfort of the occupants. There are many configurations of air distribution systems and a wide range of potential conditions inside a surgery room that are influenced by their performance. In the same way, it is evident the lack of information in the literature regarding which characteristics of the systems of air treatment have stronger influence on the amount of particles in suspension. This paper provides a review of the distribution patterns and air movement at surgery rooms, describing the importance of airborne particles in the infection process, making a comparative analysis of the efficiency of microbiological control of the main airflow systems, identifying and demonstrating the control strategies that can reduce the risks of airborne contamination in surgical infections.
\end{abstract}

Keywords: infection control, surgery rooms, air distribution, airflow systems.

\section{INTRODUCTION}

Nowadays the surgical interventions are complex and time-consuming what demands intense activities, a large team of professionals and the use of many different equipments. This situation makes increasingly important the effective control of the variables that interfere in the health, comfort and well being of the patients and of the surgical team (Dharan and Pittet, 2002).

The process of infection prevention in patients submitted to surgeries often comprises complex procedures of difficult application, involving different factors. Thus, to achieve an acceptable performance, a surgery room should accomplish a complex range of control demands. Consequently, a detailed knowledge of the characteristics of the contamination sources and of the ventilation system performance used at surgery rooms is necessary to guarantee that the ventilation system supplies the pollutant control in ventilation rates that assure health and comfort of the occupants.

The control of airborne particles, chemical and radioactive dangerous substances, odor, virus and microorganisms carried by the air, is considered essential for the protection of occupants of the surgical room (Lidwell et al., 1987; Belkin, 1998; Friberg et al., 1998). To ensure accurate control of the environmental conditions and to guarantee dilution and removal of those agents, some requirements should be considered, such as: restriction of air movement within and among sections, specific needs of ventilation and filter, and temperature and humidity control (ASHRAE, 2001).

The heating, air conditioning and ventilation (HVAC) systems carry out a fundamental task in terms of safety and thermal comfort.

There are a many configurations of air distribution systems and a wide range of potential conditions inside a surgery room that are influenced by their performance. In the same way, it is evident the lack of information in the literature regarding which characteristics of the air treatment systems have larger influence on the amount of particles in suspension.

This paper provides a review of the distribution patterns and air movement in surgery rooms, describing the importance of the airborne particles in the infection process, making a comparative analysis of the efficiency of microbiological control of the main air distribution systems, identifying and demonstrating the control strategies that can reduce the risks of airborne contamination in surgical infections. 
AIR DISTRIBUTION IN SURGERY ROOMS

\section{Turbulent Airflow Systems}

In surgical rooms that use turbulent airflow systems, conditioned air is supplied through diffusers installed at the roof (ceiling air supply) or at the wall. The air is quickly and evenly mixed with the air in the environment causing a dilution of the tenor of pollutants. So, the contamination originated by a certain source is distributed in a very uniform way along the whole room, in addition, a uniform temperature is quickly reached (Howorth, 1993; Woods et al., 1986).

The conception of air supply is vastly used in surgical centers. The turbulent distribution reduces the formation of static islands of air within the room. The project of those systems is very flexible and filters and air distribution system are less complex and of easy maintenance. However, when the airflow is small the recovery of the environment from a polluted condition is slow (Lewis, 1993).

A scheme of the air distribution pattern in a surgical room using turbulent airflow system with several diffusers located at the roof, is shown in Fig. 1. In the same way, Fig. 2 shows the air distribution pattern using turbulent airflow system with wall air supply and Fig. 3 shows the distribution pattern with diagonal air supply.

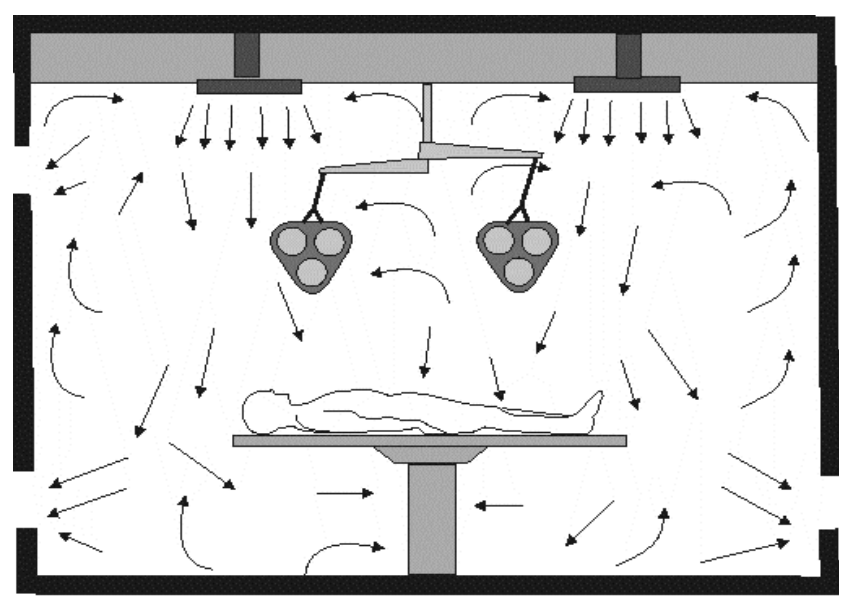

Figure 1. Conventional system (Schmidt, 1987)

\section{Laminar Airflow Systems}

The surgical systems with unidirectional airflow, also called laminar airflow, have been widely studied and are mainly used in orthopedic surgeries. In orthopedic procedures, for example in substitution of articulations, aseptic precautions should prevail to compensate the risks of the wound contamination due to the great exhibition and for massive implants, mainly when cemented (Lidwell et al., 1987; Lidwell et al., 1984; Lidwell, 1988; TAT, 1997).

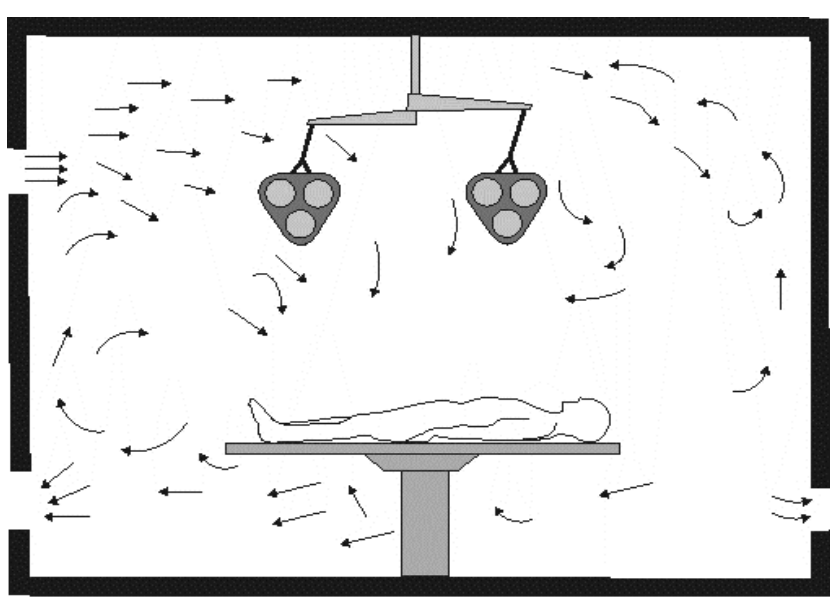

Figure 2. Conventional wall supply (turbulent) (Schmidt, 1987)

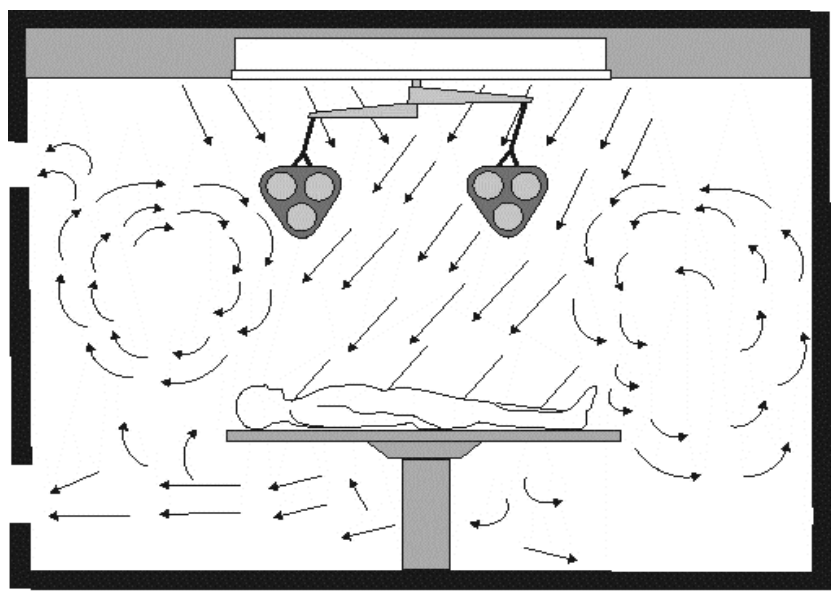

Figure 3. Diagonal system (Schmidt, 1987)

In the systems that supply unidirectional airflow the air flows evenly in a velocity of approximately $0.45 \mathrm{~m} / \mathrm{s}$, in parallel airflow lines (ASHRAE, 2002). Some concepts of unidirectional movement allow the fastest possible removal of all the contamination generated inside the environment.

In this kind of airflow the equipment can supply the air in the horizontal or vertical direction. For the former, the air is usually supplied from the whole wall, and for the latter, the supply is vertical, from the whole roof. The vertical disposition has the advantage of having the action of the gravity in helping precipitation and elimination of the larger particles, obtaining a high-efficiency system (Turpin, 1998). 
Most laminar airflow systems are equipped with high efficiency particulate air (HEPA) filters, ensuring air free from particles above $0.3 \mathrm{~mm}$ (removal of 99.97\%), removing great amount of the bacteria, fungus and even some larger viruses (TAT, 1997). This filtration assures essentially sterile air.

As mentioned in the literature (Howorth, 1993), Whitfield was the first to create a system with laminar airflow, in 1960. In 1964, Chamley developed a prototype of an encapsulated environment containing filtered air, built to hold three surgeons and a patient. In this system, the filtrated air was forced into the compartment by the upper part and the surgeons were dressing space clothes with respirators. The exhaled respiration air was extracted to avoid its mixture with the filtered air of the compartment. The objective of such a system was to eliminate the contaminations emitted by the surgeons and other sources of airborne bacteria from the surgical room.

In order to guarantee uniform air movement in a system with unidirectional flow, several types of protections are proposed, such as lateral panels and air curtains. In these types of systems, air flows parallel sweeping the whole aseptic field. The air is stratified so that cross-contamination practically does not exist. Particles eventually in suspension in a flow line tend to remain like that until being captured by the lower region of the walls (exhaustion). To guarantee uniform air movement with little mixture, the air velocity should be sufficiently high to overcome thermal drafts originated by the internal heat sources (Woods et al., 1986). A vertical laminar airflow system with lateral panels (walls) is shown in Fig. 4.

Although the systems with panels have been well succeeded regarding the microbiological air control (Friberg et al., 1998; Howorth, 1993), they impose a considerable restriction to the movements of surgeons, the other members of the surgical team and also to the positioning of instruments inside the surgical room. To avoid this kind of problems, systems with protection panels located approximately $2 \mathrm{~m}$ above the floor (Fig. 5) were proposed (Lewis, 1993; Howorth, 1993).

In laminar airflow systems with air curtains (Fig. 6), uniform flow is obtained using diffusers that supply air at the four sides of the surgical table, creating a curtain of air around this area due to the higher air velocity and the slope in relation to the vertical (Lewis, 1993; Howorth, 1993).
The air curtain becomes a physical barrier between the filtered air from the unidirectional diffusers and the polluted environment air, even at the roof level, where the air of the unidirectional diffusers is more prone to be mixed with the environment air. The curtain of air also induces the exit of the polluted air through the return grid, diluting the contamination.

Another system with lateral laminar airflow protection use plastic curtains, as shown in Fig. 7. Finally, it is also possible to use unidirectional laminar airflow systems without lateral protection (Fig. 8). These types of devices have little use in surgical rooms due to its low efficiency in the control of infectious particles. The air supplied by the diffusers can be easily mixed with the environment air by induction (Lewis, 1993; Howorth, 1993).

\section{System with Corporal Exhaustion}

One of the main sources of contamination in surgery rooms are skin fragments lost from the nude skin and also through the interstices among the fabric threads, as the cotton (Roy, 1988). The pore sizes of cotton fabric usually found at the hospitals range from $80 \mathrm{~mm}$ to $100 \mathrm{~mm}$, while the fragments of surface skin cells have an average size of $20 \mathrm{~mm}$. One person looses more than 109 epithelial cells a day and many of them carry bacteria (Belkin, 1998).

Thus, adequate garment in a surgery room helps avoiding that the contamination generated by the skin reaches the air in the environment.

In Tab. 1 some different garments and its effectiveness in the reduction of bacteria dispersion, depending on the ventilation system used, are summarized (Roy, 1988; Whyte, 1988).

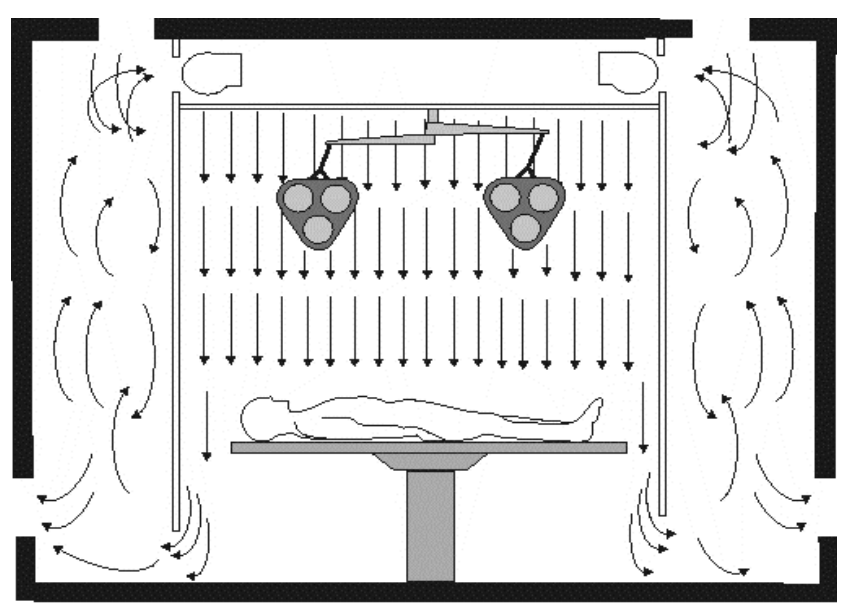

Figure 4. Vertical laminar airflow with walls (Schmidt, 1987) 


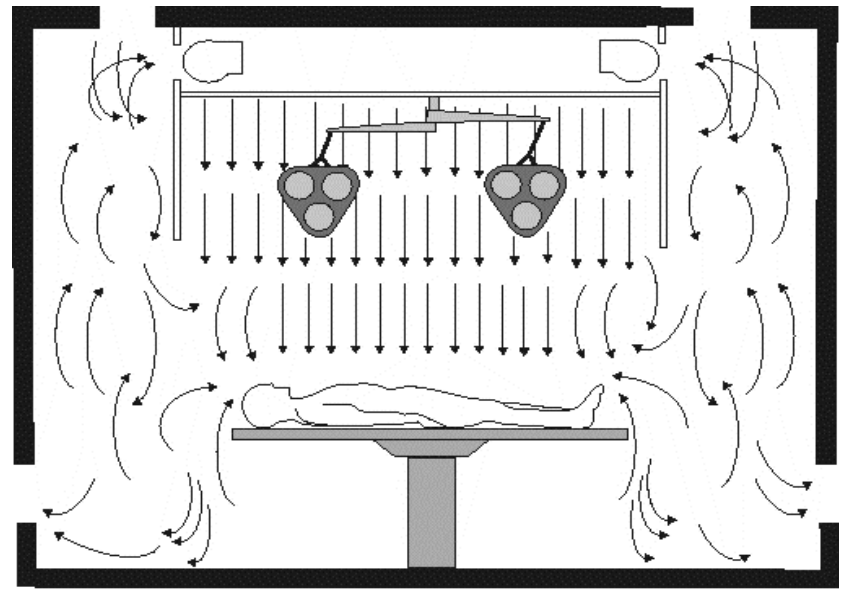

Figure 5. Vertical laminar flow with walls (2 m) (Schmidt, 1987)

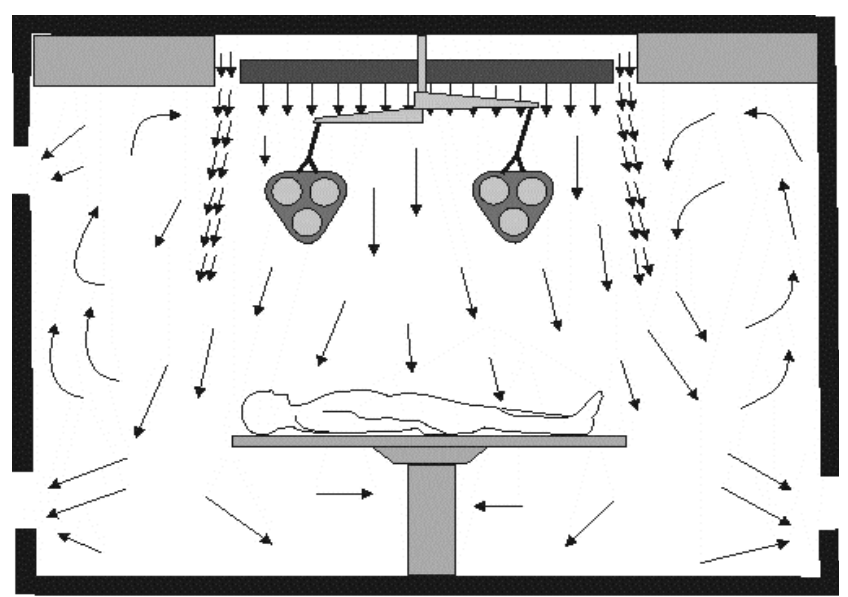

Figure 6. Air curtain around the working area (Schmidt, 1987)

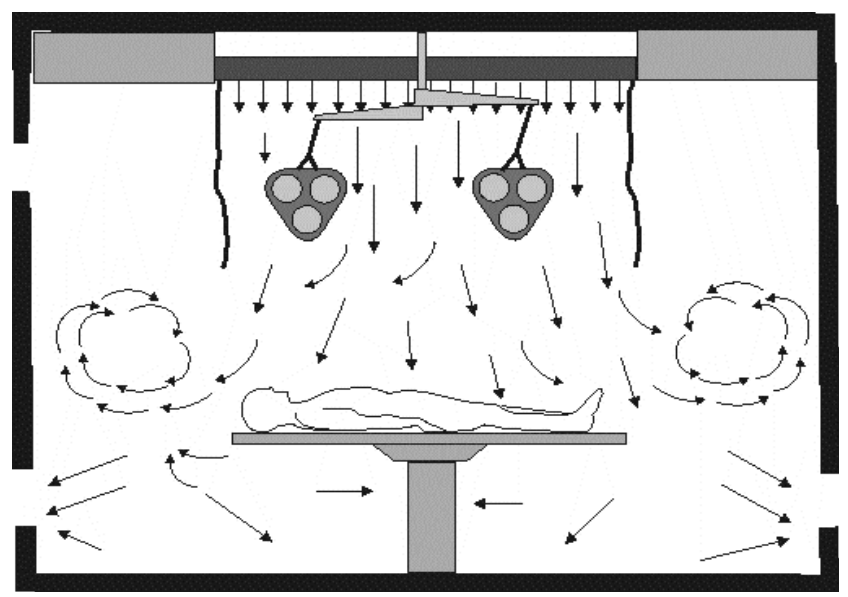

Figure 7. Unidirectional down flow with curtains (Schmidt, 1987)

The garments in surgical rooms need to have properties such that:

(a) minimize the dispersion of bacteria inside the environment;

(b) avoid that bacteria pass through the garment, and

(c) avoid bacteria to be expelled by capillary action, in case the clothes are wet.

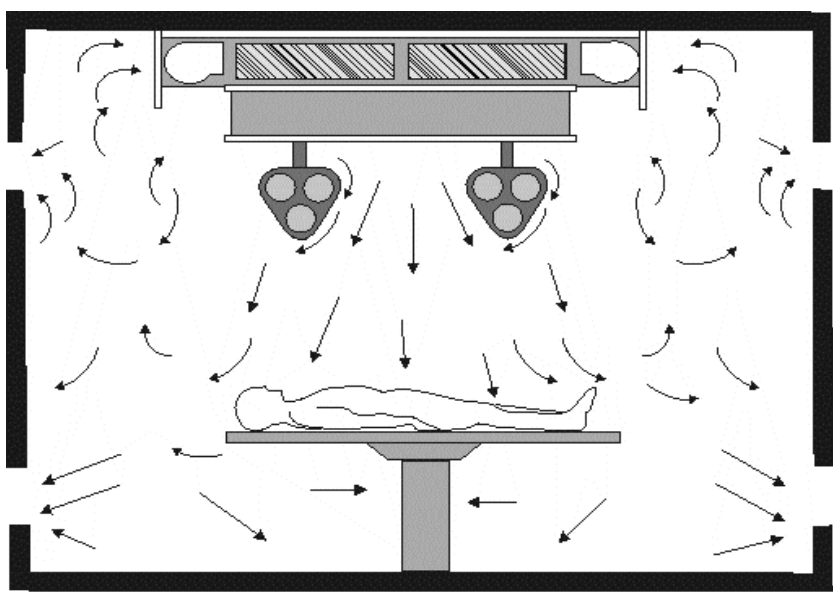

Figure 8. Unidirectional flow without protection system (Schmidt, 1987)

With the objective of removing corporal emissions, the main source of contamination of surgical wounds (Lidwell 1988; Howorth, 1993), a garment that involves the body of the surgical team from the head up to 18 inches above the floor was developed. A high enough volume of air is taken out the garment to create a negative pressure inside it, so that the air will penetrate in any opening as a consequence of the exhaustion system (Howorth, 1993).

The material that composes the garment should have low air permeability, be water impermeable and prevent the passage of bacteria to the air. Like this, all corporal emissions are removed, and the cooling and the level of oxygen are improved. An audio system is available in the garment mask to facilitate the communication.

Table 1. Airborne counts $\left(\mathrm{bcp} / \mathrm{m}^{3}\right)^{\mathrm{a}}$ in operating rooms depending on the type of clothing worn

\begin{tabular}{|c|c|c|}
\hline Clothing & $\begin{array}{c}\text { Conventionally } \\
\text { ventilated room }\end{array}$ & $\begin{array}{c}\text { Ultra-clean } \\
\text { system }^{\mathbf{b}}\end{array}$ \\
\hline Normal cotton & $100-500^{\mathbf{c}}$ & $30^{\mathrm{e}} ; 10^{\mathbf{f}}$ \\
\hline Camley exhaust gown & 50 & 0.6 \\
\hline $\begin{array}{c}\text { Disposable non-woven } \\
\text { fabrics }\end{array}$ & $50^{\mathrm{d}}$ & $1.5-2.5$ \\
\hline Close-woven fabrics & $50^{\mathrm{d}}$ & 0.7 \\
\hline
\end{tabular}

${ }^{a}$ bcp - Bacteria-carrying particles

b Unidirectional flow

c This count may vary, depending on the number of people present in the room and their level of activity d If garments are used as a complete system (i.e., shirt, trousers and gown). 
${ }^{\text {e }}$ Cross-flow system

${ }^{f}$ Down-flow system

\section{AIR DISTRIBUTION SYSTEMS EVALUATION}

\section{Turbulent Airflow Systems}

In the conventional turbulent airflow system (air supply at the roof) as well as in the conventional wall supply, turbulence occurs in the air displacement direction when the air is introduced in the environment. Due to this phenomenon, these systems can not control the distribution patterns and air movement in the surgical room (Belkin, 1998).

In the conventional wall supply system the diffusers supply air in a higher velocity, reaching a larger distribution field and provoking an increase in the turbulence along the environment. Besides, the surgical field is directly reached by the air jet provoking additional problems of thermal discomfort.

The use of the diagonal system also has the great inconvenience of increasing air turbulence in the surgical field in function of the high air supply velocity. Like this, the instruments and all of the items that get in touch with the wound will receive a random turbulence and they will lose its microbiological protection. Also, the high air velocity can provoke dehydration of the surgical wound (Howorth, 1993). Besides, movements of the surgical team will direct the jet of external air inside, introducing pollutants into the surgical field.

Another kind of problem associated with the use of turbulent airflow systems is that a negative pressure is generated in the nucleus and the whole diffuser perimeter. Thus, the polluted environment air penetrates from all sides into the diffuser center mixing with the clean supplied air. This polluted mixture of air is then dispersed in the whole surgery room (Howorth, 1993). So the polluted air inside the surgery room is being continuously contaminated by the emissions of the team and by other sources and quickly mixed with the filtered air from the HVAC system. In a study developed by Whyte (1988), it was demonstrated that surgical rooms that use these systems possess above 500 particles for cubic meter carrying bacteria.

\section{Laminar Airflow Systems}

The problem of infiltration of polluted air can also happen in some laminar airflow systems.
Some times, the descending airflow reaches the instrumentation and table level in a velocity high enough to overcome the convective ascending flows produced by hot sources, the velocity at the diffuser exit should be superior to the one of the convective flows.

According to Howorth (1993), the increase of microbiological control efficiency of these systems is very small and the operation costs are higher in comparison with turbulent systems. In some cases the diffuser occupies the whole roof along the room. Due to the great volume of air supplied by the diffuser, a reduction of the content of bacteria will certainly occur due to dilution, although followed by a high consumption of energy.

On the other hand, regarding the systems with air curtains that provide high velocity air supply in their entire periphery, tests accomplished with this type of systems show a good microbiological control (Lidwell et al. 1987; Belkin, 1998; Friberg, 1998). Besides, in the systems with protected flow, the velocity of air discharge can be smaller than that found for systems without protection, since air is to be unloaded $2 \mathrm{~m}$ from the floor.

As some authors (Whyte, 1988; Lidwell et al., 1987; Lidwell, 1988; Belkin, 1998; Friberg, 1998; NRC, 1999) point out, the system with horizontal laminar airflow does not have a lot of applications in surgical rooms due to its high degree of contamination compared to systems with vertical laminar airflow (air supply at the roof).

Figure 9 presents results obtained in a work developed by The National Resource Center NRC, which compares systems with horizontal and vertical airflow in terms of colony forming units $\left(\mathrm{CFU} / \mathrm{ft}^{3}\right)$ in function of the number of changes of air. It is observed that for both systems, the colony forming units decrease with the increase in the number of changes of air per hour (NRC, 1999).

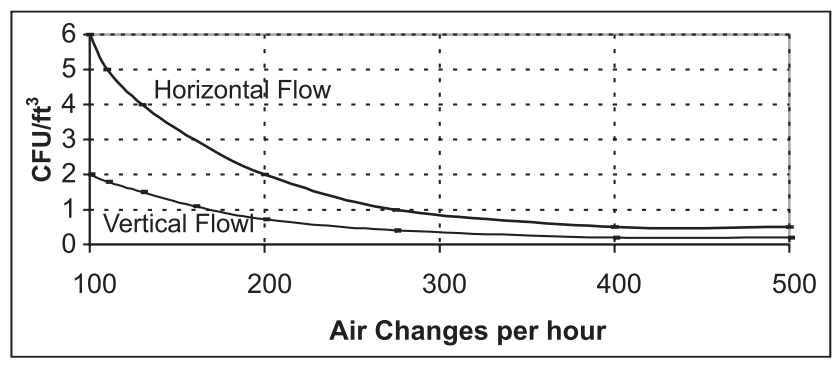

Figure 9. Airborne bacteria vs. airflow direction and air changes (NRC, 1999) 
As reported by some authors (Howorth, 1993, Friberg, 1998), systems with the diffuser centralized in the roof with exponential flow protected by air curtains are an interesting alternative. According to the authors, the exponential airflow pattern supplies a central descending flow in conjunction with a radial flow outside of the area of microbiological clean air and due to the radial outlying flow, the velocities down and outside are enough to prevent any pollutant from rising from the floor.

Fribert et al. (1998) compared three types of laminar airflow systems: system with exponential flow (protected with a wall $2 \mathrm{~m}$ above the floor), vertical system with lateral protection panel and horizontal system with lateral protection panel. According to the authors, all systems showed good microbiological control with the sampling values being within the ranged proposed by Whyte (1988), i.e, below $10 \mathrm{CFU} / \mathrm{m}^{3}$. In addition, although the three systems present a good control of the bacteriological contamination, the systems with exponential flow are the most versatile alternatives. Tables 2-4 show the results obtained by the authors for different tests.

Table 2. Air counts $\left(\mathrm{CFU} / \mathrm{m}^{3}\right)$ (Friberg et al., 1998)

\begin{tabular}{|c|c|c|c|}
\hline & $\begin{array}{l}\text { Exponential } \\
\text { (n 5) }\end{array}$ & $\begin{array}{l}\text { Vertical } \\
\quad(\mathrm{n} 5)\end{array}$ & $\begin{array}{l}\text { Horizontal } \\
\quad \text { (n 4) }\end{array}$ \\
\hline $\begin{array}{c}\text { BEFORE } \\
\text { PREPARATION }\end{array}$ & $0.2(0.2)$ & $0.2(0.1)$ & $0.1(0.2)$ \\
\hline \multicolumn{4}{|c|}{ DURING PREPARATION } \\
\hline Wound & $4.0(3.3)$ & $1.1(0.7)$ & $3.1(3.0)$ \\
\hline Instruments & $0.9(0.4)$ & $0.6(0.3)$ & $0.8(0.4)$ \\
\hline \multicolumn{4}{|c|}{ DURING SURGERY } \\
\hline Wound & $1.3(0.5)$ & $0.8(0.3)$ & $1.9(0.3)$ \\
\hline Instruments & $2.3(1.1)$ & $1.2(0.9)$ & $0.05(0.03)$ \\
\hline
\end{tabular}

Table 3. Sedimentation $\left(\mathrm{CFU} / \mathrm{m}^{2} / \mathrm{h}\right)$ (Friberg et al., 1998)

\begin{tabular}{lccc}
\hline & $\begin{array}{c}\text { Exponential } \\
(\mathrm{n} \mathrm{5})\end{array}$ & $\begin{array}{c}\text { Vertical } \\
(\mathrm{n} 5)\end{array}$ & $\begin{array}{c}\text { Horizontal } \\
(\mathrm{n} \text { 4) }\end{array}$ \\
\hline \multicolumn{4}{c}{ OUTSIDE LAMINAR FLOW } \\
$653(170)$ & $864(365)$ & $90(53)$ \\
\hline \multicolumn{4}{l}{ INSIDE LAMINAR FLOW } \\
Patient chest & $64(35)$ & $58(32)$ & $72(106)$ \\
Wound & $39(51)$ & $64(40)$ & $32(37)$ \\
Instruments & $26(38)$ & $7(13)$ & $32(45)$ \\
\hline
\end{tabular}

Table 4. Particle counts (particles $/ \mathrm{m}^{3}$ ) in the wound area (Friberg et al., 1998)

\begin{tabular}{cccc}
\hline & $\begin{array}{c}\text { Exponential } \\
(\mathrm{n} 5)\end{array}$ & $\begin{array}{c}\text { Vertical } \\
(\mathrm{n} 5)\end{array}$ & $\begin{array}{c}\text { Horizontal } \\
(\mathrm{n} \text { 4) }\end{array}$ \\
\hline$>0.3$ & $2084(3531)$ & $1978(5156)$ & $27426(18413)$ \\
$>5.0$ & $141(212)$ & $247(742)$ & $1153(307)$ \\
$>10.0$ & $106(141)$ & $177(586)$ & $929(285)$ \\
\hline
\end{tabular}

Schmidt (1987) presents more detailed comparisons of airflow systems on the concentration of infectious particles in the surgical field. The author studied several types of airflow systems as well as their variations. However, specific data of the systems project were not included. Other medical comparisons were not included, such as real occurrence of postoperative infections, statistical comparisons between the different surgery types and relative effectiveness of other possible medical interventions. Besides, the systems are not the same regarding undesirable interactions or their aspects. Figure 10 shows the data published by this author.

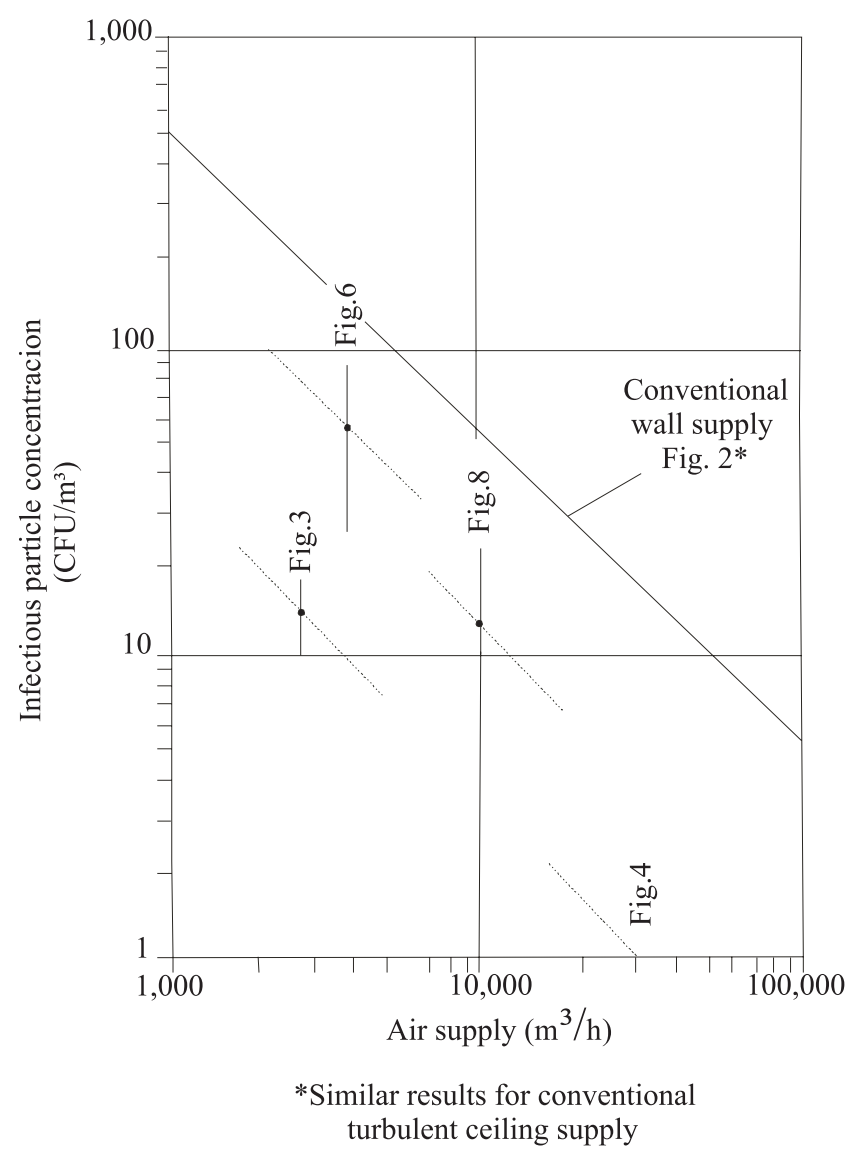

Figure 10. Influence of the of airflow system of the surgical field on the concentration of infectious particles (Schmidt, 1987) 


\section{Systems with Corporal Exhaustion}

Pasquarella et al. (2003) compared bacteriological counts in surgeries with the use of clothes with corporal exhaustion systems and conventional clothes. The studies were carried out in surgical rooms with conventional turbulent airflow systems. According to the authors the use of corporal exhaustion did not demonstrate considerable reductions in the level of bacteriological contamination when compared to conventional clothes.

\section{SYSTEMS PERFORMANCE INFECTION CONTROL}

AND

The Council of Medical Researches, together with the Department of Health and Social Welfare in England, carried out an extensive study monitoring more than 8000 surgeries of replacement of hip and knee joints. The results demonstrated that the combination of prophylactic antibiotics, adequate clothes to reduce dispersion of particles and air treatment systems designed to carry bacteria away from the surgical wound produced a reduction in the incidence of infections that fell to just a few cases in one thousand surgeries (Lidwell et al., 1987; Lidwell, 1988).

In the work of Lidwell et al. (1987) interesting observations are presented. According to the authors, the incidence of infection was of $0.6 \%$ in patients whose joint implant was inserted in ventilated surgical rooms with laminar airflow system, compared with $1.5 \%$ in patients whose operation had been carried out in rooms with conventional ventilation. In this study, joint infections were confirmed with a new surgery performed one to four years after the first surgery. The scope of this study did not include a strictly controlled test of the effect of the antibiotic prophylaxis. The authors concluded that the infection levels were reduced from $2 \%$ to $1 \%$ only with the use of laminar airflow and from $2 \%$ to $0.5 \%$ with the use of laminar airflow and Chamley corporal exhaustion.

\section{NUMERICAL SIMULATION}

Due to the limitations of the experimental approach and to the rapid development in computational fluid dynamics (CFD) technology, comprehensive airflow analysis of the entire room space has become feasible (Chow and Yang, 2003). The CFD has proven very powerful and efficient in parametric studies of room airflow and contaminant dispersion (Chen et al, 1992; Chow and Yang, 2003; Hartung et al, 1998; Memarzadeh and Jiang, 2000).

The developments were based on the work of Launder and Spalding in the early 1970s. Within the context of fluid mechanics, the determination of room airflow and particulate distribution requires solving the continuity and momentum equations in three dimensions. A computational model for predicting the contaminant (particle) distribution comprises two numerical parts. Firstly, the airflow pattern must be determined. Secondly, substituting the already known velocity field into the equation of particle motion, a complete particle path can be obtained.

The most common CFD techniques are direct numerical simulation (DNS), large-eddy simulation (LES), and the Reynolds averaged Navier-Stokes (RANS) equations with turbulence models. Each technique handles turbulence in a different manner.

The most popular RANS model is the standard k- $\varepsilon$ model developed by Launder and Spalding in the early 1970s (Chow and Yang, 2003).

\section{CFD Modeling of Airflow in Surgery Rooms}

CFD modeling of particle transport has been applied for the control of airborne particles in the operating zone above the surgery table in an operating room (Chen et al, 1992; Hartung and Kugler, 1998; Memarzadeh and Jiang, 2000). Figure 11 shows the use of the technique of numerical simulation in the study of the air movement in a surgery room (Liu et al., 2003)

Chen et al. (1992) successfully conducted the numerical simulation of airflow and particle concentration in a surgery room. The authors made use of a modified low-Reynolds number $\mathrm{k}-\varepsilon$ model and verified that the airflow within the sterilized zone is basically unidirectional, but it is basically turbulent outside that zone.

Hartung and Kugler (1998) conducted a two-dimensional numerical modeling of a surgical room. The authors suggested that the surgical team and lamps can affect the airflow. However, twodimensional modeling is inadequate for any kind 
of realistic representation of the flow field and particle transport.

a)

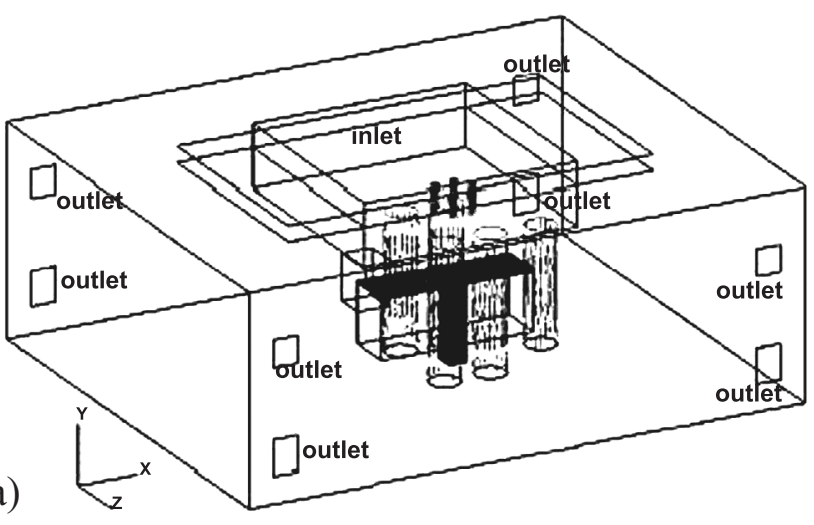

b)

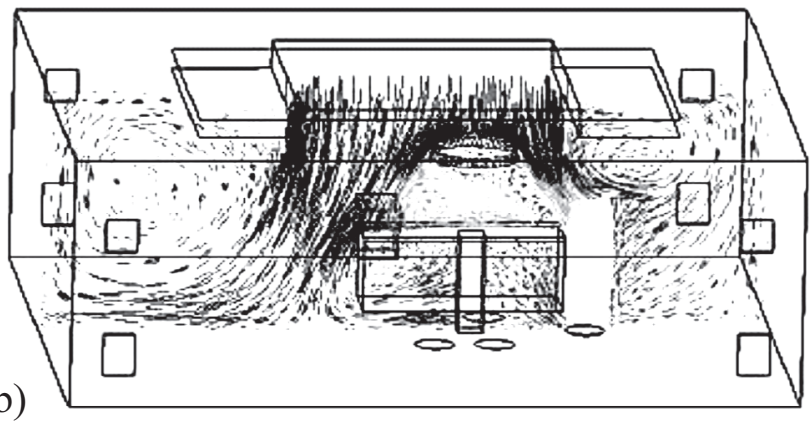

Figure 11. Computational fluid dynamics simulation of a surgery room. (a) General layout, (b) Airflow pattern (Liu et al., 2003)

Memarzadeh and Jiang (2000) used a k-e turbulence model and particle tracking procedure to study the effects of the ventilation system and ultraviolet germicidal irradiation on minimizing the risk from airborne organisms in isolation rooms in Canada.

In other work, Memarzadeh and Manning (2002) used airflow modeling and particle-tracking methodologies to compare the risk of contaminant deposition on an operating room surgical site and back table from different ventilation systems.

In a case study of a teaching hospital, Kameel and Khalil (2003) applied a SIMPLE numerical algorithm with the turbulence characteristics represented by a modified model to account near-wall functions. Optimum air distribution system was found to depend mainly on the air supply, the extract outlet positions and the operating table orientation. Similar conclusions were reached when Liu and Moser (2002) carried out CFD analysis on a real operating room in a Swiss hospital. It has been found that particle source location, air (supply) inlet design, operating table location, and lamp design are among the critical parameters determining particle distribution within the surgery room (Liu et al., 2003).

In a CFD analysis supported by field measurements in a surgical room in Hong Kong Hospital, Chow and Yang (2003) simulated temperature distribution, airflow pattern and contaminant dispersion. The study emphasized health risks of airborne bacteria released from the surgical team on the patient, and vice versa.

\section{CONCLUDING REMARKS}

In a surgery room, there is a group of factors associated to the environment air that can bring risks to the occupants and especially to the patients due to their low resistance. So, it is extremely important in surgery rooms the adoption of control procedures to prevent airborne contamination and preserve health and welfare of the occupants.

Several studies indicate that some surgery room airflow systems can reduce the levels of postoperative infection. However there is a lack of data in the literature analyzing the specific characteristics of the systems. There are many studies on the sources and paths of the infection for several types of air treatment systems, with appropriate statistical methods to justify the conclusions. However, these studies do not present necessary design and performance data for the establishment of efficiency criteria.

\section{ACKNOWLEDGEMENTS}

The authors wish to acknowledge FAPESP (São Paulo State Foundation for Research Support) for the financial support received to develop a research on "Systems of air treatment in surgery rooms: Study of the distribution of particles in the evaluation of airborne contamination", through the Research Grant No. 2004/01247-0.

\section{REFERENCES}

ASHRAE, 2002, Handbook of Applications. Atlanta: American Society of Heating, Refrigerating and Air-Conditioning Engineers, Inc.

ASHRAE, 2001, Handbook of Fundamentals. Atlanta: American Society of Heating, Refrigerating and Air-Conditioning 
Engineers, Inc.

Belkin, L. N., 1998, Laminar Airflow and Surgical Wound Infections, AORN Journal, August.

Chen, Q., Jiang, Z., and Moser, A., 1992,

Control of Airborne Particle Concentration and Draught Risk in an Operating Room. Indoor Air 2, pp. 154-167.

Chow, T., and Yang, X., 2003, Performance of Ventilation System in a Non-standard Operating Room., Division of Building Science and Technology, City University of Hong Kong, Hong Kong SAR, China.

Dharan, S., and Pittet, D., 2002, Environmental Controls in Operating Theatres, Journal of Hospital Infection, Vol. 51, No. 2, pp. 79-84.

Friberg, B. E. E., Burman, L. G., and Friberg, S., 1998, Zoned Exponential, Vertical and Horizontal Ultra-Clean Laminar Airflows. Acta Orthopaedica Scandinavica, Vol. 69, No. 2, pp. 169-172.

Friberg, B., 1998, Ultraclean laminar airflow in operating rooms, AORN Journal, April.

Hartung, C., and Kugler, J., 1998, Perturbations Affecting the Performance of Laminar Flow in Operating Theatres, $15^{\text {th }}$ IFHE CONGRESS, pp. 88-92.

Howorth, F. H., 1993, Prevention of Airborne Infection during Surgery, ASHRAE Transactions, Vol. 91, No. PT 1B, pp. 291-304.

Kameel, R., and Khalil, E., 2003, Predictions of Turbulence Behavior Using k-e Model in Operating Theatres. Mechanical Power Engineering Dpt, Cairo University, Egypt.

Lewis, J. R., 1993, Operating Room Air Distribution Effectiveness, ASHRAE Transactions, 99, No. 2, pp. 1192-1200.

Lidwell, O. M., 1988, Air, Antibiotics and Sepsis in Replacement Joints. Journal of Hospital Infection. Vol. 11 (Suppl. C), pp. 18-40.

Lidwell, O. M., Lowbury, E. J. L., Whyte, W., Blowers, R., Stanley, S. J., and Lowe, D., 1987, Ultraclean Air and Antibiotics for Prevention of Postoperative Infection: a Multicenter Study of 8052 joint replacement operations. Acta Orthopaedica Scandinavica, Vol. 58, No. 1, pp. 4-13.

Lidwell, O. M., Lowbury, E. J. L., Whyte, W., Blowers, R., Stanley, S. J., and Lowe, D., 1984, Infection and Sepsis after Operations for Total Hip or Knee-joint Replacement: Influence of Ultraclean Air, Prophylactic Antibiotics and other Factors. Journal of Hygiene, Vol. 93, No. 3, pp. 505-529.
Liu, Y., and Moser, A., 2002, Airborne Particle Concentration Control for an Operating Room, Roomvent, Copenhagen, Denmark.

Liu, Y., Moser, A., and Kazuyoshi, H., 2003, Numerical Study of Airborne Particle Transport in an Operating Room, International Journal of Ventilation, Vol. 2, No. 2, pp. 103-110.

Memarzadeh, F., and Manning, A. P., 2002, Comparison of Operating Room Ventilation Systems in the Protection of the Surgical Site. ASHRAE Transactions, Vol. 108, Part 2, pp. 3-15.

Memarzadeh, F., and Jiang, J., 2000, Methodology for Minimizing Risk from Airborne Organisms in Hospital Isolation Rooms. ASHRAE Transactions, Vol. 106, pp. 731-747.

NRC - The National Resource Center, Operating Room Ventilation - A Guide to Engineering Desing \& Operating, The National Resource Center, 1999.

Pasquarella, C., Pitzurra, O., Herren, T., Poletti, L., and Savino, A., 2003, Lack of Influence of Body Exhaust Gowns on Aerobic Bacterial Surface Counts in a Mixed-Ventilation Operating Theatre, Journal of Hospital Infection, Vol. 54, No. 1, pp.2-9.

Roy, M. C., 1988, The Operating Theater: A Special Environmental Area. In: Prevention and Control of Nosocomial Infections, pp. 514-38.

Schmidt, P., 1987, Air Control in Operating Theatres. Heizung Luftung Haus Technik, Vol. 38, No. 3, pp. 145-153.

Turpin, I. M., 1998, Laminar Airflow Systems, AORN Journal, September.

TAT - Technology Assessment Team, 1997, An Overview of Laminar Flow Ventilation for Operating Theatres. Policy Coordination Unit.

Whyte, W., 1988, The Role of Clothing and Drapes in the Operating Room Journal of Hospital Infection, 11, supplement C, pp. 2-17.

Woods, J. E., Brayman, D. T., Rasmussen, R. W., Reynolds, G. L., and Montag, G. M., 1986, Ventilation Requirements in Hospital Operating Rooms. Part I: Control of Airborne Particles. ASHRAE Transactions, 92, No. PT 2A, pp. 392-426. 